\title{
Understanding and modifying the impact of parents' substance misuse on children
}

\author{
Richard Velleman \& Lorna Templeton
}

Abstract We outline the huge literature on the potentially negative impact on children of growing up with a parent who has an alcohol or drug problem, the risk factors that can exacerbate this effect, and resilience and the protective factors that can reduce it. Clear ways that practitioners can intervene to reduce risk and to increase resilience are discussed. All practitioners have a responsibility to work in holistic ways if damage to children and families is to be avoided, and we summarise the key common skills needed to work with individuals (children as well as adults) and families. The differences between a resilience and a deficit approach are outlined.

Substance misuse has been described as a 'great and growing evil' (Royal College of Physicians, 1987) within the UK. Although alcohol enjoys a special status in our society, as the only psychoactive drug that is both socially acceptable and legally available to adults without prescription (Roberts et al, 2001), it is also the cause of huge social and medical problems (Velleman \& Templeton, 2005a). According to the National Alcohol Harm Reduction Strategy for England, alcohol misuse is currently costing the UK around $£ 20$ billion a year, including the cost of crime and antisocial behaviour, alcoholrelated health problems, loss of productivity in the workplace and domestic violence (Prime Minister's Strategy Unit, 2004). This national strategy document indicates that around 50\% of all violent crimes and, at peak times, up to $70 \%$ of all admissions to accident and emergency departments are linked to alcohol misuse. The health effects of alcohol consumption in the UK can be seen in data showing that, between the periods 1987-1991 and 1997-2001, the number of men dying from cirrhosis more than doubled in Scotland and rose by over two-thirds in England and Wales. Deaths of women from cirrhosis increased by almost half. These increases are the steepest in western Europe, and contrast with a decline in most other countries, particularly those of southern Europe (Leon \& McCambridge, 2006). Similarly, the number of alcohol-related deaths in England and Wales, which rose throughout the 1980s and 1990s, has continued to rise in more recent years. For males, the death rate per 100000 population has increased from 5.5 in 1983 to 15.8 in 2003 (Office for National Statistics, 2005). The number of drink-related hospital admissions in England has also increased by more than a quarter in 8 years, from 39913 in 1996-97 to 51108 in 2004-05, a rise of $28 \%$ (BBC, 2005).

The situation as far as illegal drugs is concerned, although not so dire, is also problematic (Velleman \& Templeton, 2005b). In 2000, a government survey in England and Wales found that about $13 \%$ of men and $8 \%$ of women (aged between 16 and 75 ) reported using illegal drugs in the previous year (Office for National Statistics, 2001). Many more of these were aged 20-40 than 40-75, and more men than women reported using. The number of problem drug users in the UK is hard to estimate, but the same survey suggested that the prevalence of drug dependence was 37 per 1000 people aged between 16 and 75 (which is exactly half of the prevalence found for alcohol dependence). For 20- to 24-year-olds, however, the rate rose to 94 per 1000 for women and 199 per 1000 for men (i.e. nearly $10 \%$ of all women in this age group and nearly $20 \%$ of all men).

Almost 4 million people in the 16-65 age group in the UK are dependent on alcohol and/or drugs.

Richard Velleman is Professor of Mental Health Research and Director of the Mental Health Research and Development Unit (MHRDU, Wessex House, Level 7, University of Bath, Bath BA2 7AY, UK. Email: R.D.B.Velleman@Bath.ac.uk), a joint unit of Avon \& Wiltshire Mental Health Partnership (AWP) NHS Trust and the University of Bath. A clinical psychologist, Richard has set up statutory addictions services, helped develop the families and psychosis service within AWP and worked as an NHS trust board director. He has undertaken numerous research projects and published very widely, especially on the impact of addiction in families. Lorna Templeton is deputy manager and a senior researcher at the MHRDU, where she also manages the alcohol, drugs and the family research programme. Lorna has chaired and is a current committee member of the New Directions in the Study of Alcohol Group, and is a committee member of the Addictions Forum and of Alcohol Concern's Children and Families Forum. She has worked in the research field since the early 1990s, having worked previously at the National Addiction Centre in London and the Addiction Research Foundation in Toronto, Canada. 


\section{Box 1 Structures and functions within the family often disrupted by alcohol or drug misuse}

- Rituals: the ways families celebrate religious or family occasions such as Christmas or birthdays

- Roles: as one family member develops a substance problem, others take over their roles, such as finances, disciplining, shopping and cleaning

- Routines: when behaviour becomes unpredictable it creates difficulties for the family in planning or committing to routines: will she remember to collect her son from school? When will he come home, and in what state?

- Communication: alcohol and drugs have a major effect on communication between family members

- Social life: families tend to become increasingly socially isolated, owing to the difficulty of explaining to friends and neighbours that a family member has a drug or alcohol problem, or the social embarrassment or unpredictability associated with drinking and drugs

- Finances: a family's finances can be hugely affected by reduction in income (e.g. owing to job loss) and spending of such income as is obtained on alcohol or drugs instead of more vital items

- Relationships and interactions: for example both the misuser and their partner may become much more neglectful of other family members; aggression and violence are much more likely: more than $80 \%$ of cases of violence between spouses are alcohol-related and $20-30 \%$ of child abuse cases involve parents who are heavy drinkers (similar findings arise with the families of problem drug users)

Assuming (conservatively) that every substance misuser will negatively affect at least two of their close family, this suggests that about 8 million family members (spouses, children, parents, siblings) in the UK are living with the negative consequences of someone else's drug or alcohol misuse. These numbers apply to those dependent on alcohol or illicit drugs. They exclude the more than 9 million people who drink at hazardous or risky levels, and the resultant 18 million family members potentially affected by them. Also excluded are people who take drugs at sufficiently risky levels to threaten their family's well-being. These exclusions are important: the fact is that most problems resulting from substance misuse (whether for the user or for their family) are not caused by people who are seriously dependent or 'addicted'. Most 'problem' drinking or drug-taking is done by people who use alcohol or drugs inappropriately or in an unsafe or hazardous manner. In this article problem use is defined as any that causes problems to the person doing it or to someone else.

Problem drinking and drug-taking are worldwide phenomena; and many people who use substances in problematic ways are also parents. Their behaviour, therefore, can have significant consequences for their children, either through its effect on the family as a whole or on the child directly (Copello et al, 2005).

\section{The impact on children}

The negative impact of problems arising from parental substance misuse (particularly alcohol and illegal drugs) on children (Cleaver et al, 1999; Harbin \& Murphy, 2000; Tunnard 2002a,b; Kroll \& Taylor,
2003; Barnard \& McKeganey, 2004; Gorin, 2004) and young adults (Velleman \& Orford, 1999) has been well documented (Velleman, 2004), and has been acknowledged in two key government publications (Advisory Council on the Misuse of Drugs, 2003; Prime Minister's Strategy Unit, 2003).

Box 1 outlines the common structures and functions within the family that are often disrupted by alcohol or drug misuse. Box 2 describes some of the common negative experiences that children and

Box 2 Negative experiences of children and adolescents living with parental substance misuse $^{1}$

- High levels of violence

- Experiencing or witnessing neglect or abuse - physical, verbal or sexual

- Poor and/or neglectful parenting

- Inconsistency from one or both parents

- Having to adopt responsible or parenting roles at an early age

- Feeling negative emotions such as shame, guilt, fear, anger and embarrassment

- Possibleneurodevelopmental consequences of substance misuse in pregnancy (e.g. foetal alcohol syndrome) that may contribute to developmental delays or intellectual disability

1. A fully referenced version of this information appears as Box DS1 in a data supplement to the online version of this article on our website (http:// apt.rcpsych.org). 
adolescents may have when living with a parent with a substance misuse problem. These and other disruptions can have a strong impact on children at all stages of their development, placing them at risk of developing a wide range of problems (Box 3). Many children affected by problem substance use within the family environment will reach the attention of social services because of concerns regarding child protection (Forrester \& Harwin, 2004). The issues outlined in Boxes 2 and 3 relate to both alcohol and drug misuse, but additional problems can arise when the parent misuses illicit drugs. These include the illegal nature of drug misuse, the modes of ingestion, the links to crime, the use of the family home for groups of people to take drugs (drug misuse is more likely to be a home-based activity), and the even stronger links with poverty, unemployment and social deprivation.

Factors in parents' lives and relationships have the potential to exacerbate the problems summarised in Boxes 1-3 (Cleaver et al, 1999; Velleman \& Orford, 1999; McKeganey et al, 2002). These factors, which are summarised in Box 4 , have a cumulative effect: the more that are present, the higher the risk of negative outcomes.

\section{Resilience}

From the issues outlined above it is easy to see why commentators have been pessimistic about the future of children brought up in such an environment. However, in recent years it has become evident that, for some children, rather different outcomes might be possible. It seems that not all individuals are adversely affected, either as children or as adults (West \& Prinz, 1987; Tweed \& Rhyff, 1991; Cleaver et al, 1999; Velleman \& Orford, 1999; Tunnard, $2002 a, b)$. There seem to be factors and processes that can minimise the negative impact of parental drug or alcohol misuse, or protect against them. Thus, some children are resilient and develop no significant problems related to their parents' substance misuse.

\section{Box 3 Negative effects of living with a parent with a substance misuse problem ${ }^{1}$}

\section{Children}

Children who have the experiences outlined in Box 2 often subsequently demonstrate their negative effects, including higher levels of:

- behavioural disturbance, antisocial behaviour (conduct disorders)

- emotional difficulties

- behavioural problems and underachievement at school

- social isolation, because they feel that it is too problematic or shameful to bring friends home, or because they are not able to go out with friends as they have responsibilities of caring for other family members (e.g. siblings or the misusing parents)

- 'precocious maturity'

They also tend to have a more difficult transition from childhood to adolescence and increased likelihood of being referred to social services because of child protection concerns

\section{Adolescents}

Two common patterns often emerge:

- increasing introspection and social isolation, with friendship difficulties (e.g. the young person is unlikely to visit or invite friends to their own home), anxiety or depression (for which psychoactive medication may be prescribed); attempts to escape their family home (e.g. by leaving home at an early age or entering into a long-term relationship)

- development of strong peer relationships which are kept separate from their own family; these relationships may themselves involve early alcohol or drug use, participation in sub-cultures perceived to be 'deviant', in antisocial activity, unsafe sex and unplanned and/or early pregnancy

Adulthood

- Some of the problems of childhood and adolescence can continue into adulthood

- There is some (although not as great as previously thought) evidence that adult offspring of substance-misusing parents have greater problems in terms of substance misuse or areas of adulthood adjustment

1. A fully referenced version of this information appears as Box DS2 in a data supplement to the online version of this article on our website (http:/ /apt.rcpsych.org). 
Box 4 Risk factors leading to generally worse outcomes

General factors

- High levels of family disharmony

- Domestic violence

- Physical, sexual or emotional abuse

- Inconsistent, ambivalent or neglectful parenting

- The absence of a stable adult figure (such as a non-using parent, another family member or a teacher)

- Parental loss following separation or divorce

- Material deprivation and neglect

- The family not seeking help

Substance-specific factors

- Both parents being substance misusers

- Substance misuse taking place in the home

- Greater severity of the problem

Drug-related factors

- Exposure to and awareness of criminal activity (e.g. drug dealing)

- Presence of the child (although not necessarily in the same room) when drugs are taken

- Witnessing someone inject drugs and seeing paraphernalia (e.g. lying around the home)

\section{Evidence for resilience}

There is considerable evidence that children can grow up in all sorts of difficult circumstances (not just with substance misuse) without developing significant problems. This research is not confined to children in families in which there are substance misuse problems: it seems to be a general finding (e.g. Gilligan, 2000; Friedman \& Chase-Lansdale, 2002; Newman, 2002; Luthar, 2003).

A study that followed 698 individuals from birth to the age of 35 allowed identification of protective factors in children exposed to challenging family environments as they grew up, and clarification of how these developed and changed through the life cycle (Werner, 1993). About 200 of the children were classified in a high-risk cohort typified by a disharmonious family environment (including parental alcoholism). A third of this cohort 'grew into competent, confident and caring young adults. None developed serious learning or behavioural problems in childhood or adolescence ... [They] succeeded in school, managed home and social life well, and expressed a strong desire to take advantage of whatever opportunity came their way' (p. 504).
A number of studies have focused on the effects of parental alcohol misuse (Velleman \& Orford, 1993a,b, 1999). One such study (Velleman \& Orford, 1999) included 244 adults aged 16-35 years; 164 were the children of problem drinkers; the remaining 80 formed a 'normal' comparison group matched for age and recruitment source. It identified many of the risk factors shown in Box 4 for the offspring of problem drinkers, but many of the sample who had experienced a very deleterious upbringing seemed to be as well-functioning, happy and successful as those in the comparison group (p. 246).

\section{Resilience and protective factors}

Resilience should be conceptualised as a process, rather than a static trait and/or something solely internal to the individual (Rutter, 1987; Masten et al, 1990; Werner, 1993; Glantz \& Johnson, 1999; Little et al, 2004). And as a process it is the product of an interaction between the individual and their social context: hence, it is potentially open to influence.

It is useful to distinguish between protective factors (which make it more likely that a child will develop resilience) and evidence that the child is being resilient. Resilience is self-perpetuating: behaving in a resilient way increases the probability of further resilient behaviour.

Protective factors and resilience have been identified in a number of studies, both general and specific to parental substance misuse (e.g. Werner, 1993; Velleman \& Orford, 1999; Beinart et al, 2002; Bancroft et al, 2004). For example, Bancroft et al (2004) interviewed 37 young people aged $15-27$ who were children of substance-misusing parents, and found that a number of protective factors could lead to more resilient outcomes. These included support from school, immediate and extended family, and individuals and services outside of the family. It should not be thought, however, that this was easy to maintain. Although the participants in this study said that some support from immediate and extended family was obtainable and was certainly beneficial, they also said that longer-term, unconditional support was rare, and certainly nowhere near the level they needed or desired. Strategies used to deal with the misuse included escape (e.g. spending time in their room or going to visit friends) and challenging the user (although this latter was rarely successful). In common with participants in other studies (e.g. Velleman \& Orford, 1999), the young people interviewed by Bancroft et al were helped to move on from their difficult pasts by their own actions: identifying goals and dreams and making them happen; making the most of education or work opportunities; moving away from their parents; and 
developing their lives through their own family and children. A central issue in their success was the feeling that they had choices and were in control of their lives.

A list of the protective factors and evidence of consequent resilience, gleaned from the studies we have reviewed, is given in Box 5 .

The key issue for resilience is the overcoming of psychological risk (Rutter, 1987; Friedman \& ChaseLansdale, 2002). Protective factors make it more likely that a child can overcome this risk because they provide a more positive setting. Resilience makes this more likely because it equips the child with a set of skills and feelings that enable him (or her) to be forward-looking and to bounce back from adversity.

\section{Box 5 Protective factors and resilience}

\section{Protective factors}

- The presence of a stable adult figure (usually a non-substance misuser)

- Close positive bond with at least one adult in a caring role (e.g. parents, older siblings, grandparents)

- A good support network beyond this

- Little separation from the primary carer in the first year of life

- Parents' positive care style and characteristics

- Being raised in a small family

- Larger age gaps between siblings

- Engagement in a range of activities

- Individual temperament

- Positive opportunities at times of life transition

- Continuing family cohesion and harmony in the face of the misuse and its related effects (e.g. domestic violence, serious mental health problems)

Evidence of resilience that these protective factors encourage

- Deliberate planning by the child that their adult life will be different

- High self-esteem and confidence

- Self-efficacy

- An ability to deal with change

- Skills and values that lead to good use of personal ability

- A good range of problem-solving skills

- Feeling that there are choices

- Feeling in control of own life

- Previous experience of success and achievement
It is also clear that developmental changes and stages, and interactions with other factors (such as gender, temperament, parent-child relationships, marital support, planning, school experiences and early parental loss) at key transition points in life, can have a particular impact on the development of resilience (Rutter, 1987; Werner, 1993; Cleaver et al, 1999).

\section{Is resilience always positive?}

A few notes of caution must be sounded in relation to resilience. All strategies have potential associated risk; their success or levels of benefit are by no means guaranteed. This means that the processes that allow young people to become resilient may not all be totally positive, either in the short or the long term.

For example, strategies that are beneficial and effective for a young child may be harmful in the longer term (e.g. Velleman \& Orford, 1999; Kroll \& Taylor, 2003; Bancroft et al, 2004). For example, strategies of detachment, avoidance and withdrawal such as those noted by Werner \& Johnson (1999), who described detachment from 'family members whose domestic and emotional problems threaten to engulf them', are often very effective when used by a powerless child. However, they can result in attachment and relationship difficulties when these children grow older. Along the same lines, in the longitudinal study mentioned above, Werner (1993) noticed that some of the sample were detached from things and people: 'they had learned to keep the memories of their childhood adversities at bay by being in the world but not of it'. Learning to get on with their own life may make people seem aloof or detached.

Not everyone can make use of each protective strategy. Although the research outlined above found the support of friends to be an important protective factor for young people, the same research reported that many individuals, particularly younger children, found it hard to make friends. Similarly, although many young people tended to leave home earlier than they otherwise might have done, wanting to escape and try to achieve independence, adulthood and normality, a number of these young people were left feeling that they had lost their childhood and youth, and some were at risk of developing their own problems (with substances, early pregnancy, housing difficulties, etc.)

\section{The essence of resilience}

Most people deal with adversity, on a greater or smaller scale, on a daily basis. Few of us lead such 
cushioned lives that we do not sometimes face challenges and change. What is so unique about 'resilience'? Glantz \& Sloboda (1999: p. 113) believe that "part of the essential character of "resilience" seems to be that the positive outcome was unexpected ... a model or theory fails to accurately predict behaviour for some individuals'. Hence, the level of difficulty faced by many children of parents with serious substance use problems is such that theory predicts they will develop problems in turn (Friedman \& Chase-Lansdale, 2002).

Others have suggested that resilience is a basic human characteristic that might be lost in some individuals because of the depth of the problems they face, problems that lead to such a loss of confidence and self-esteem that their natural resilience cannot easily be instituted. Thus, the capacity for resilience is within us all; it is just hidden sometimes and needs teasing out. Bancroft et al (2004), who studied older children of substance-misusing parents, write that resilience did not necessarily mean growing up or being stronger: it 'involved creating space to focus on themselves and their needs, and to have fun, without responsibilities for others ... they were often having to relearn, or learn for the first time, the joys and pleasures of being young, or being able to focus on themselves and their own needs' (p. 78). It is important to get it right in youth, because resilience, much like other traits and characteristics, is amenable to change in childhood, but starts to stabilise through adolescence and adulthood: if you get it right earlier, you are more likely to keep it right.

Interventions to build resilience are not concerned with developing something unusual: they are concerned with enabling young people to develop a characteristic that is inherent in basic human adaptational systems (Flynn et al, 2004). Interventions may therefore be more about raising awareness of the possibilities of resilience and putting into place strategies for promoting such resilience.

\section{Modifying the impact: what can practitioners do?}

Thus, there is clear evidence that some children are resilient, and that there are identifiable factors that seem to be associated with both their protection and their resilience. But can practitioners do anything to promote resilient outcomes? We believe that there are two clear ways in which they can:

- by working to reduce the risks to children (the fewer risk factors, the more likely it is that children will not be negatively affected)

- by working to increase protective processes and factors (the more of them there are, the more likely it is that children will be resilient).
Clearly both of these activities will involve not just the child, but the family and, possibly, wider social networks. There is a good body of evidence (not reviewed here) that interventions aimed at the family and social networks can also lead to positive therapeutic change (Copello et al, 2005, 2006).

\section{Reducing risk}

As we outlined above, a key finding is that promoting a safe and stable family environment (maintaining family roles and rituals, ensuring family harmony) is vital, and that the major risk factors relate to such family issues, as opposed to the drinking or drugtaking in themselves.

All of these major risk factors are amenable to intervention, even if the parental substance misuse is not at the time. This means that practitioners working with families in which parents have substance misuse problems should not necessarily focus their risk-reduction efforts on enabling the substance misuser to change (although, of course, if this is a possibility it should be encouraged). Instead, they need to work on:

- family disharmony, in particular

- violence (including physical, verbal or sexual abuse)

- parental conflict

- parental separation and loss

- inconsistent, neglectful and ambivalent parenting.

These things seem to pose the greatest risk to the short- and long-term well-being of children. Moreover, they can all be worked on using the skills and techniques (conflict resolution, anger management, couples counselling, parenting skills training) that are available in most practitioners' toolboxes.

\section{Increasing protective factors and resilience}

The second way that practitioners can help to promote resilience is to work on protective factors and resilience itself. As far as protective factors are concerned, clinicians can work with:

- the other parent (if there is one and if they do not also have a substance problem), enabling them to provide a stable environment and give the time and attention that children require

- the parental relationship, enabling parents to retain its cohesion and present a united and caring front to the children

- the family, ensuring that family relationships, family affection and family activities are maintained 
- adult figures outside of the nuclear family, ensuring that there is at least someone who can provide the necessary stabilising influence.

This work might involve direct intervention with other key adult figures, for example grandparents or teachers. In a qualitative study of 62 drug-using parents in Scotland, Barnard (2003) reported that the extended family's involvement in caring for the children and supporting the parents was pivotal to the children's well-being. Most importantly, they found a clear correlation between the absence of such support and the child being taken into local authority care. These factors within a child's environment will mean that they are more protected and hence more likely to develop resilience.

Resilient children (and adults) share key characteristics: planning, high self-esteem and confidence, self-efficacy, the ability to deal with change, problemsolving skills, the feeling that they have choices and are in control, and previous experience of success and achievement. The task for practitioners, therefore, is to enable vulnerable children and young people to develop these attributes. Essentially, within the remit of a professional role that will dictate the level of contact with and responsibility for a child, practitioners can use this relatively basic knowledge of protective factors to contribute to the child's development of resilience. The practitioner needs to work directly with the children involved, enabling them to:

- maintain positive family rituals

- remove themselves from the disruptive behaviour of the problem parent or parents

- disengage from the disruptive elements of family life

- engage with stabilising people outside the family

- develop 'confidants' outside the family

- engage in stabilising activities (school, clubs, sports, culture, religion) within which the child can develop a sense of self and self-esteem

- develop a desire to be, and pride in being, a survivor.

A key task of the practitioner in developing children's resilience, then, is to help them to identify and build on their strengths, including the social support they can call on, enabling them to build meaning and motivation into their lives, helping them to acquire social skills that bring self-control, self-esteem and a sense of humour (Little et al, 2004), and helping them to reframe negative events and emotions into positive ones.

Obviously, interventions should take into account the age, gender and developmental level of the child. For example, it may be more difficult for younger children to seek external support: there may be problems with transportation, money, parents' permission, protection and safety. Girls seem less affected by parental problem-drinking in the short term but if the situation continues then there is an increased likelihood of problems developing(Cleaver et al, 1999). Werner (1993) also found that individual disposition was more important for females, whereas external support was more important for males. Boys often feel that conflict is more of a threat to them, whereas girls tend to appraise conflict in terms of how it affects them and are more likely to blame themselves (Reynolds, 2001). The setting in which the intervention is undertaken can also be important: this work with children need not be conducted in individual counselling or case-work sessions: there is evidence that a group approach can be effective in promoting resilience in young people with stressful backgrounds, including parental substance misuse (Waaktaar et al, 2004).

Gilligan (2000) and Newman (2002) offer further and more detailed guidance on increasing individuals' resilience. Although not written specifically for work with children who have experienced parental substance misuse, there is much within these two guides that is useful for such a situation.

\section{Key commons skills and contexts}

Many child care practitioners have told us that they lack the skills to work with substance-misusing parents in order to reduce risk factors or increase protective factors for children. Strangely, many practitioners in substance misuse services tell us the converse: that they do not have the skills to work with children and the wider family to the same purpose. Our response to both groups is that all practitioners use the same basic skills of forming a therapeutic relationship and counselling (Velleman, 2001). These skills are listed in Box 6.

\section{Box 6 Key skills of psychotherapy and counselling}

For work with anyone (adult or child) the clinician needs to:

- be warm, empathic and genuine

- make a therapeutic relationship

- help clients to explore their difficulties

- enable clients to set achievable goals

- empower clients to take action to reach these goals

- stay with clients and help them to stabilise and maintain changes 
Clearly, especially with younger children, such skills must sometimes be used slightly differently or alongside other techniques, such as art or play therapy. Clearly also, specific therapeutic techniques such as conflict resolution, couples counselling, parenting skills training, and so on may also be useful, as might therapeutic interventions aimed at enabling the adult family members to change (Copello et al, $2005,2006)$. But the essential skills base remains the same. Overall, skilled helpers (Department of Health, 2004) use the same key core skills, irrespective of the age of the person with whom they are working or the number of people present in the room.

\section{Responsibilities and holistic contexts}

Even when practitioners have the skills, many feel that it is not their role to work with children, or families or parents with substance misuse problems. We take the view that we all have both clinical and moral responsibilities to think about the wider systems and not solely about our identified and referred 'patients'. Indeed, the possibility that any case might involve child protection issues is a powerful argument for services to take a broader view of their remit. Hence, in any adult healthcare service, practitioners need to know whether the adult they are helping has children and family, and what impact that person's problems and behaviour may be having on those family members. Similarly, in child and adolescent services, practitioners must be alert to the influence on children of their parents' problems. And 'alert' does not simply imply onward referral. Very often practitioners need to intervene in a more holistic and systemic way, and not imagine that intervening with the child in the absence of their problem parents, or the adult in the absence of their wider family, will lead to a successful outcome: dealing with the impact of parents' substance (or mental health) problems on their children is an issue not just for child and adolescent mental health services: it is the responsibility of all healthcare practitioners. The report on the inquiry into the death of Victoria Climbié, a child under the care of social services, made it clear that practitioners could no longer walk away from situations that might put anyone, child or adult, at risk (House of Commons Health Committee, 2003).

The key points here are that as practitioners we can intervene to help these children; and that the focus does not have to be on the parental substance misuse problem, but on promoting necessary beneficial factors in children's lives. This is especially important: one of the main myths in the substance misuse field is that there is nothing that anyone can do (about anything) unless the substance
Box 7 Traditional, risk-focused ideas about parental substance misuse

- Genetic risk: children of substance-misusing parents are at particular and specific risk of developing behavioural and substance misuse problems of their own

- Co-dependency: the children of alcoholics and addicts will suffer particular and significant problems when they are children and are at risk of developing problems (most likely with substances and relationships) in adulthood

misuser decides to change their substance misuse behaviour. This is entirely untrue: there is a very large amount of evidence that significant change can be brought about by focusing on other issues, and even by intervening with key family members in the absence of the substance-misusing adult (Copello $e t$ $a l, 2005)$. In the context of this article, which focuses on children, it is vital that practitioners do not get sidetracked into concentrating solely on parental problems: instead we must focus on the child's needs and how to meet them.

\section{Resilience $v$. deficit}

Historically, theory, practice and research in health and social care have been preoccupied with illness, vulnerability and the pathology of life's problems (Richardson et al, 1990; Friedman \& Chase-Lansdale, 2002). This has been the case in the substance misuse field too, where deficit models that focus on risk and negative short- and long-term outcomes have been the dominant way of thinking about the impact that parental substance misuse has on children and young people.

More recently (Flynn et al, 2004) there has been a growing interest in positive psychology and 'posttraumatic growth', which has been defined as 'the potential for positive change through trauma and suffering' (Linley, 2000). This approach focuses more on health and well-being and the positive aspects of life's problems: on what 'keeps people healthy, rather than what makes them sick' (Newman, 2002). This shift has included the emergence of the concept of resilience, both as a philosophical approach and as a practical way of understanding and working with people affected by a range of problems. Linley, for example, highlights research that has demonstrated positive adaptation following traumatic events as varied as the sinking of a cruise ship, life-threatening illness and sexual abuse. 
The concept of resilience therefore introduces a new theoretical framework for thinking about the children of substance-misusing parents (Box 7). Resilience is important because it implies that some children, even if they live in disadvantageous circumstances, either are resilient or have the capacity to become so. Thus, it is not a foregone conclusion that all children who live in such circumstances are, or will be, damaged. This has major implications for both intervention and policy. It suggests that intervention should not wait until a crisis is reached and damage is apparent. Neither should it focus solely on reducing risk factors. There is much that can be done early in the child's life to promote factors associated with greater resilience, and to encourage the development of resilience in children who are at increased risk of experiencing greater problems. As Werner (1993) argued, 'our examination of the long-term effects of childhood adversity and of protective factors and processes in the lives of highrisk youths has shown that some of the most critical determinants of adult outcomes are present in the first decade of life'. Waiting for problems to occur often makes offering help more difficult. There are many policy implications here for greater and earlier preventive interventions.

\section{Conclusions}

We believe that it is relatively clear how professionals can help families to reduce risk, develop protective factors and promote resilience in young people (Box 8). However, further work is needed to encourage and train professionals to use this knowledge to work in a more focused and integrated way, looking at the full range of a child's needs within a broader context.

\section{Box 8 Key learning points}

- It is relatively clear how professionals can help to modify the impact of parental substance misuse on children: they should help them to reduce risk, develop protective factors and promote resilience

- Practitioners can intervene, and the focus does not have to be on the substance misuse, but on providing necessary beneficial factors in children's lives

- Practitioners must not be sidetracked into focusing on the parents' problems: the focus must be on the child's needs and how to meet them

\section{Declaration of interest}

None.

\section{References}

Advisory Council on the Misuse of Drugs (2003) Hidden Harm: Responding to the Needs of Children of Problem Drug Users. The report of an Inquiry by the Advisory Council on the Misuse of Drugs. TSO (The Stationery Office).

Bancroft, A., Wilson, S., Backett-Milburn, K., et al (2004) Risk and Resilience: Older Children of Drug and Alcohol Misusing Parents. Joseph Rowntree Foundation.

Barnard, M. (2003) Between a rock and a hard place: the role of relatives in protecting children from the effects of parental drug problems. Child and Family Social Work, 8, 291-299.

Barnard, M. \& McKeganey, N. (2004) The impact of parental problem drug use on children: what is the problem and what can be done to help? Addiction, 99, 552-559.

BBC News (2005) 'Hospital alcohol admissions rise'. http:// newswww.bbc.net.uk/1/hi/uk/4562276.stm

Beinart, S., Anderson, B., Lee, S., et al (2002) Youth at Risk? A National Survey of Risk Factors, Protective Factors and Problem Behaviour among Young People in England, Scotland and Wales (JRF Findings 432). Joseph Rowntree Foundation.

Cleaver, H., Unell, I. \& Aldgate, J. (1999) Children's Needs Parenting Capacity. TSO (The Stationery Office).

Copello, A., Velleman, R. \& Templeton, L. (2005) Family interventions in the treatment of alcohol and drug problems. Drug and Alcohol Review, 24, 369-385.

Copello, A., Templeton, L. \& Velleman, R. (2006) Family intervention for drug and alcohol misuse: is there a best practice? Current Opinion in Psychiatry, 19, 271-276.

Department of Health (2004) The Ten Essential Shared Capabilities: A Framework for the Whole of the Mental Health Workforce. Department of Health.

Flynn, R., Ghazal, H., Legault, L., et al (2004) Use of population measures and norms to identify resilient outcomes in young people in care: an exploratory study. Child and Family Social Work, 9, 65-79.

Forrester, D. \& Harwin, J. (2004) Social work and parental substance misuse. In Children Exposed to Parental Substance Misuse: Implications for Family Placement (ed. R. Phillips), pp. 115-131. British Agencies for Adoption and Fostering.

Friedman, R. \& Chase-Lansdale, P. (2002) Chronic adversities. In Child and Adolescent Psychiatry (4th edn) (eds M. Rutter \& E. Taylor), pp. 261-276. Blackwell.

Gilligan, R. (2000) Promoting Resilience: A Resource Guide on Working with Children in the Care System. British Agencies for Adoption and Fostering.

Glantz, M. \& Johnson, J. (1999) (eds) Resilience and Development: Positive Life Adaptations. Kluwer Academic/Plenum Publishers.

Glantz, M. \& Sloboda, Z. (1999) Analysis and re-conceptualization of resilience. In Resilience and Development: Positive Life Adaptations (eds M. Glantz \& J. Johnson), pp. 109-126. Kluwer Academic/Plenum Publishers.

Gorin, S. (2004) Understanding What Children Say. Children's Experiences of Domestic Violence, Parental Substance Misuse and Parental Health Problems. National Children's Bureau.

Harbin, F. \& Murphy, M. (2000) (eds) Substance Misuse and Child Care: How to Understand, Assist and Intervene when Drugs Affect Parenting. Russell House Publishing.

House of Commons Health Committee (2003) The Victoria Climbie Inquiry Report. Sixth Report of Session 2002-2003. Report and Formal Minutes together with Oral Evidence. TSO (The Stationery Office).

Kroll, B. \& Taylor, A. (2003) Parental Substance Misuse and Child Welfare. Jessica Kingsley.

Leon, D. \& McCambridge, J. (2006) Liver cirrhosis mortality rates in Britain from 1950 to 2002: an analysis of routine data. Lancet, 367, 52-56. 
Linley, A. (2000) Transforming psychology... The example of trauma. Psychologist, 13, 353-355.

Little, M., Axford, N. \& Morpeth, L. (2004) Research review: risk and protection in the context of services for children in need. Child and Family Social Work, 9, 105-117.

Luthar, S. (2003) (ed.) Resilience and Vulnerability: Adaptation in the Context of Childhood Adversities. Cambridge University Press.

Masten, A., Best, K. \& Garmezy, N. (1990) Resilience and development. Contributions from the study of children who overcome adversity. Development and Psychopathology, 2, 425-444.

McKeganey, N., Barnard, M. \& McIntosh, J. (2002) Paying the price for their parents' addiction: meeting the needs of the children of drug-using parents. Drugs: Education, Prevention and Policy, 9, 233-246.

Newman, T. (2002) Promoting Resilience: A Review of Effective Strategies for Child Care Services. Centre for Evidence-based Social Services \& Barnados.

Office for National Statistics (2001) Psychiatric Morbidity among Adults Living in Private Households. ONS.

Office for National Statistics (2005) Alcohol-related Death Rates in England and Wales, 2001 to 2003. ONS. http:/ / www.statistics. gov.uk/cci/nugget.asp?id=1091

Prime Minister's Strategy Unit (2003) National Alcohol Harm Reduction Strategy: Interim Analysis. Strategy Unit. http:// www.number10.gov.uk/files/pdf/SU\%20interim_report2. pdf

Prime Minister's Strategy Unit (2004) Alcohol Harm Reduction Strategy for England (NAHRSE). Strategy Unit. http://image. guardian.co.uk/sys-files/Society/documents/2004/03/15/ alcoholstrategy.pdf

Reynolds, J. (2001) Not in Front of the Children: How Conflict Between Parents affects Children. One Plus One Marriage and Partnership Research.

Richardson, G., Neiger, B., Jensen, S., et al (1990) The resiliency model. Health Education, 21, 33-39.

Roberts, M., Fox, C. \& McManus, J. (2001) Drink and Disorder: Alcohol, Crime and Anti-Social Behaviour. Nacro Publications.

Royal College of Physicians (1987) A Great and Growing Evil: The Medical Consequences of Alcohol Abuse. Royal College of Physicians.

Rutter, M. (1987) Psychosocial resilience and protective mechanisms. American Journal of Orthopsychiatry, 57, 316331.

Tunnard, J. (2002a) Parental Problem Drinking and its Impact on Children. Research in Practice. http://www.rip.org.uk/ publications/documents/researchreviews / ALCOHOL. pdf

Tunnard, J. (2002b) Parental Drug Misuse: A Review of Impact and Intervention Studies. Research In Practice. http://www.rip. org.uk/publications/documents/researchreviews/drugs_ misuse.pdf

Tweed, S. \& Rhyff, C. (1991) Adult children of alcoholics: profiles of wellness amidst distress. Journal of Studies on Alcohol, 52, 133-141.

Velleman, R. (2001) Counselling for Alcohol Problems (2nd edn). Sage.

Velleman, R. (2004) Alcohol and drug problems in parents: an overview of the impact on children and implications for practice. In Seriously Disturbed and Mentally Ill Parents and their Children (2nd edn) (eds M. Gopfert, J. Webster \& M. Seeman), pp. 185 - 202. Cambridge University Press.

Velleman, R. \& Orford, J. (1993a) The importance of family discord in explaining childhood problems in the children of problem drinkers. Addiction Research and Theory, 1, 39-57.

Velleman, R. \& Orford, J. (1993b) The adulthood adjustment of offspring of parents with drinking problems. British Journal of Psychiatry, 162, 503-516.

Velleman, R. \& Orford, J. (1999) Risk and Resilience: Adults Who Were the Children of Problem Drinkers. Harwood Academic.

Velleman, R. \& Templeton, L. (2005a) Alcohol use and misuse. In Key Topics in Public Health (ed. L. Ewles), pp. 177-196. Elsevier.
Velleman, R. \& Templeton, L. (2005b) Drug use and misuse. In Key Topics in Public Health (ed. L. Ewles), pp. 197-220. Elsevier.

Waaktaar, T., Christie, H., Borge, A., et al (2004) How can young people's resilience be enhanced? Experiences from a clinical intervention project. Clinical Child Psychology and Psychiatry, 9, 167-183.

Werner, E. (1993) Risk, resilience and recovery. Perspectives from the Kauai Longitudinal Study. Development and Psychopathology, 5, 503-515.

Werner, E. \& Johnson, J. (1999) Can we apply resilience? In Resilience and Development: Positive Life Adaptations (eds M. Glantz \& J. Johnson), pp. 259-268. Academic Press/Plenum Publishers.

West, M. \& Prinz, R. (1987) Parental alcoholism and childhood psychopathology. Psychological Bulletin, 102, 204-218.

\section{MCQs}

1 In the UK:

a more people have problems with drugs than with alcohol

b more people use alcohol hazardously than use drugs hazardously

c $50 \%$ of all violent crimes are linked to drug misuse

d liver cirrhosis deaths are rising slower that they are in other western European countries

e in the 20-24 age group, survey results suggest that nearly $20 \%$ of all women and nearly $10 \%$ of all men are drug dependent.

2 Parental substance misuse problems:

a generally affect only the misuser, and not their children

b generally have an impact on young children, with adolescents escaping most ill-effects

c affect children more if the misuser is the mother

$\mathrm{d}$ affect children more if the misuse takes place in the family home

e reduce the likelihood of violence in the family home.

\section{Resilience is:}

a a static trait, internal to the individual

$\mathrm{b}$ a process that is rarely open to influence

c different from protective factors, which increase the chances of a child being more resilient

d a defence mechanism created by a child who feels worthless, unwanted and lacks confidence

e extremely difficult to encourage if it is not there innately.

4 Interventions with children who live in difficult circumstances should:

a wait until a crisis is reached and damage is apparent

b focus solely on reducing risk factors

c start as early as possible in order to promote factors associated with greater resilience

$\mathrm{d}$ be made only by specialist child and adolescent psychiatrists

e involve the professional making a very long-standing commitment to working with the child and their family. 
5 Therapeutic skills needed to work with the children of substance misusers and the misusing parent:

a fundamentally differ for each group

$\mathrm{b}$ require expertise in techniques such as motivational interviewing and relapse prevention

c involve helping them explore their difficulties, set goals, take actions and maintain subsequent changes

d require further training in child psychotherapy and/or family therapy

e involve reassurance and risk reduction while referring on to CAMHS or a specialist substance misuse team.

\section{MCQ answers}

$\begin{array}{llllllll}\text { 1 } & & \text { 2 } & & 3 & & & 5 \\ \text { a F } & \text { a F } & \text { a F } & \text { a F } & \text { a F } \\ \text { b T } & \text { b F } & \text { b F } & \text { b F } & \text { b F } \\ \text { c F } & \text { c F } & \text { c T } & \text { c T } & \text { c T } \\ \text { d F } & \text { d T } & \text { d F } & \text { d F } & \text { d F } \\ \text { e F } & \text { e F } & \text { e F } & \text { e F } & \text { e F }\end{array}$

